\title{
Quality assurance of the Brewer spectral UV measurements in Finland
}

\author{
K. Lakkala ${ }^{1}$, A. Arola ${ }^{2}$, A. Heikkilä ${ }^{2}$, J. Kaurola ${ }^{2}$, T. Koskela ${ }^{2}$, E. Kyrö ${ }^{1}$, A. Lindfors ${ }^{2}$, O. Meinander ${ }^{2}$, A. \\ Tanskanen $^{2}$, J. Gröbner ${ }^{3}$, and G. Hülsen ${ }^{3}$ \\ ${ }^{1}$ Finnish Meteorological Institute, Arctic Research Centre, Sodanlylä, Finland \\ ${ }^{2}$ Finnish Meteorological Institute, Helsinki, Finland \\ ${ }^{3}$ Physikalisches Meteorologisches Observatorium Davos, World Radiation Center, Davos Dorf, Switzerland
}

Received: 14 December 2007 - Published in Atmos. Chem. Phys. Discuss.: 29 January 2008

Revised: 13 May 2008 - Accepted: 19 May 2008 - Published: 30 June 2008

\begin{abstract}
The quality assurance of the two Brewer spectrophotometers of the Finnish Meteorological Institute is discussed in this paper. The complete data processing chain from raw signal to high quality spectra is presented. The quality assurance includes daily maintenance, laboratory characterizations, calculation of long-term spectral responsivity, data processing and quality assessment. The cosine correction of the measurements is based on a new method, and is included in the data processing software. The results showed that the actual cosine correction factor of the two Finnish Brewers can vary between 1.08-1.13 and 1.081.12 , respectively, depending on the sky radiance distribution and wavelength. The temperature characterization showed a linear temperature dependence between the instruments' internal temperature and the photon counts per cycle, and a temperature correction was used for correcting the measurements. The long-term spectral responsivity was calculated using the time series of several lamps using two slightly different methods. The long-term spectral responsivity was scaled to the irradiance scale of the Helsinki University of Technology (HUT) for the whole of the measurement time-periods 1990-2006 and 1995-2006 for Sodankylä and Jokioinen, respectively. Both Brewers have participated in many international spectroradiometer comparisons, and have shown good stability. The differences between the Brewers and the portable reference spectroradiometer QASUME have been within 5\% during 2002-2007.
\end{abstract}

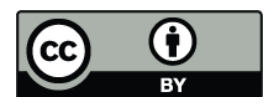

Correspondence to: K. Lakkala (kaisa.lakkala@fmi.fi)

\section{Introduction}

Many spectral UV measurement programs started at the end of the 1980s, after it was recognized that the stratospheric ozone content was declining not only over Antarctica but also over the Arctic and in mid-latitudes (Booth et al., 1992; WMO, 1990). Decrease in total ozone is observed as a wavelength-dependent increase in UV radiation. Particularly, spectral measurements are needed to assess the influence of the ozone depletion on the ecosystem, as the biologically most effective solar radiation is that at short UV wavelengths (Young et al., 1993). Measuring the complete UV spectrum offers many possibilities for various different kinds of research, compared with measuring the UV radiation using a broadband instrument. The challenge is to maintain the sensitivity of the instrument at all wavelengths, as the dynamical range of the UV is huge. Well-characterized and -maintained high-precision spectroradiometers are needed to detect the possible, even though small, changes at these wavelengths (Seckmeyer et al., 2002).

The Brewer spectrophotometer MK II \#037 of the Finnish Meteorological Institute (FMI) at Sodankylä, Finland (lat. $67^{\circ} \mathrm{N}$ ), was installed in 1988 to monitor total column ozone at this site influenced by Arctic ozone depletion (Kyrö et al., 1992; Von der Gathen et al., 1995). Since 1990 it has also monitored spectral UV radiation, and the UV time series for Sodankylä is one of the longest in Europe. The time series has been homogenized, and constitutes a continuous record since then. A second Brewer spectrophotometer was installed in the observatory at Jokioinen, Finland (lat. $61^{\circ} \mathrm{N}$ ), in 1995. The Brewer is a MK III-type spectrophotometer \#107, which fulfills the WMO level S-2 requirements

Published by Copernicus Publications on behalf of the European Geosciences Union. 
Table 1. The Brewer spectrophotometers of the Finnish Meteorological Institute and their characteristics.

\begin{tabular}{|c|c|c|}
\hline & Brewer \#037 & Brewer \#107 \\
\hline $\begin{array}{l}\text { location } \\
\text { start of UV meas. } \\
\text { surroundings } \\
\text { monochromator } \\
\text { diffuser } \\
\text { wavelength range }\end{array}$ & $\begin{array}{l}\text { Sodankylä }\left(67^{\circ} \mathrm{N}, 27^{\circ} \mathrm{E}\right) \\
1990 \\
\text { forest and swamp } \\
\text { single } \\
35 \mathrm{~mm} \text { Teflon, quartz dome } \\
290-325 \mathrm{~nm}\end{array}$ & $\begin{array}{l}\text { Jokioinen }\left(61^{\circ} \mathrm{N}, 24^{\circ} \mathrm{E}\right) \\
1995 \\
\text { fields and forest } \\
\text { double } \\
35 \mathrm{~mm} \text { Teflon, quartz dome } \\
\qquad \rightarrow 24.4 .1997: 290-363 \mathrm{~nm} \\
25.4 .1997-9.11 .1997: 286.5-363 \mathrm{~nm} \\
11.11 .1997 \rightarrow \quad: 286.5-365 \mathrm{~nm}\end{array}$ \\
\hline
\end{tabular}

(Seckmeyer et al., 2002) for detection of trends in UV irradiance. Both spectral UV time series have been used in many studies and have thus served the scientific community in the study of UV features for more than 15 years (Gardiner and Kirsch, 1997; Bais et al., 2001; De Backer et al., 2001; Meinander et al., 2003; Arola et al., 2003b; Lakkala et al., 2003; Lindfors et al., 2003; Glandorf et al., 2005; Gröbner et al., 2005; Huttunen et al., 2005; Kazantzidis et al., 2006; Meinander et al., 2006; Arola et al., 2007; Lindfors et al., 2007; Tanskanen et al., 2007).

In this paper, we present the complete data processing of the FMI's Brewer spectrophotometers from raw signal to quality-controlled UV spectra. This includes a new way of processing the spectral responsivity time series and correcting for temperature dependence and cosine error. The terminology 'quality control' and 'quality assurance' is based on Webb et al. (2003). Sections 2, 3, 4 and 5 deal with the quality control, describing the standard operating procedures, laboratory characterizations, long-term spectral responsivity and the data processing. The quality assurance itself is discussed separately in Sect. 6, using the inductive method described by Webb et al. (2003). There, the quality of the measurements is evaluated using comparisons with other independent spectral measurements as well as comparisons with reconstructed UV values. The flagging of the European data base (EUVDB) is also used as an independent quality statement.

Bernhard and Seckmeyer (1999) have reviewed the various sources of uncertainty in spectral UV measurements, and Webb et al. (1998) have described calibration and quality control procedures. Several papers about the quality assurance procedures of broad-band or multichannel UV instruments (Blumthaler, 2004; Bernhard et al., 2005; Lakkala et al., 2005; Josefsson, 2006) have been published. Previous papers about the complete data processing procedure of spectral UV measurements have been published for the SUVtype spectroradiometers of the National Science Foundation (NSF) network (Booth et al., 2001; Bernhard et al., 2004) and for the two Brewer spectrophotometers of the Aristotle University of Greece in Thessaloniki (Garane et al., 2006).

\section{Standard operating procedures}

We start by presenting the standard operating procedures of the two Brewer spectrophotometers of the FMI, including the routine stability check and daily quality control. The characteristics of the two Brewers are presented in Table 1.

\subsection{Lamp measurements}

The spectral stability of the Brewers is monitored by $50 \mathrm{~W}$ and $1000 \mathrm{~W}$ lamp measurements. The $50 \mathrm{~W}$ lamps are measured every second week outdoors and every second week in the laboratory dark-room. The $1000 \mathrm{~W}$ lamps have been measured in the laboratory on average every month, since 1997 at Jokioinen and 1998 at Sodankylä. The 1000 W lamp dark-room measurements are performed following a standard procedure in order to achieve measurements of the highest accuracy. Both the temperature of the dark room and the current of the lamp are controlled. The intensity of the calibration lamp is also recorded by both a UV-B and a UV-A sensor; the current and voltage of the lamp are recorded as well. These are used to monitor the stability of the lamp during an individual calibration event, but not to determine any long-term stability (Koskela, 1999). All reflecting surfaces are covered with black cloths, and baffles are used in order to minimize diffuse light.

Several lamps are measured each time so that the lamps are burned for different amounts of time, as recommended in Webb et al. (1998). Thus some lamps are used more frequently, while others are burned only a few times per year. This enables distinguishing drifts related to the ageing of an individual lamp to be recognized.

\subsection{Maintenance}

The daily operation routine consist of a series of measurements, which depend on the solar zenith angle. The measurement series is mostly started at constant air masses, where two types of measurement are performed: global UV radiation measurements and total ozone measurements using direct sky or zenith sky measurements. Between the 
measurements, certain routine checks are automatically performed. For example, standard lamp measurements allow to follow the daily stability of the instrument, and mercury lamp measurements are made regularly to ensure the right wavelength alignment at $296.7 \mathrm{~nm}$. At both stations the spectrum is recorded typically every half-an-hour in steps of $0.5 \mathrm{~nm}$. The total scanning time is around 3 and 6 min for Sodankylä and Jokioinen, respectively. At the end of the day, the raw data is automatically transfered to a data base, and daily measurement events are listed.

Maintenance, including a regular check of levelling and cleaning is performed by the operators of the sounding station. Each operator has been trained in the correct operation of the instrument and use of the control software. The Brewer stands on a tripod, the levelling of which is checked at least every time the instrument is replaced there after e.g. a darkroom calibration.

The Arctic conditions represent special challenges to the instruments. As frost is a problem during the winter, air is blown on the diffuser in order to keep it as dry as possible and free from frost. Whenever an operator is at work, the dome is also cleaned after rain and snow. In order to keep the inside of the Brewer dry, nitrogen gas is circulated through it. At both sites, the outside temperature can be $-30^{\circ} \mathrm{C}$ during winter time; at Sodankylä the temperature falls to $-40^{\circ} \mathrm{C}$ almost every winter. In order to keep the interior temperature above zero degrees, both Brewers have heating elements inside the instrument.

\subsection{Ancillary measurements}

As Sodankylä and Jokioinen are both synoptical weather stations, many different types of ancillary measurements are available. From the point of view of the UV radiation measurements, the most important of these are related to sky condition, e.g., clouds and precipitation. The snow depth is recorded, and has been related to surface albedo (Arola et al., 2003a). Continuous radiation measurements are maintained routinely, e.g., global, direct, diffuse and reflected global radiation measurements are available. As well as the Brewer measurements, total ozone column measurements are available from SAOZ measurements. Ozone soundings are performed once a week at Sodankylä. Both stations have carried out PFR-type (Precision Filter Radiometer) aerosol optical depth measurements since 2004 (Wehrli, 2000; Aaltonen et al., 2006). Many other air quality and atmospheric composition measurements are available at both stations as well.

In addition to these standard radiation measurements, Brewer-scan-synchronized broadband UV and global pyranometer measurements were started in 2001 and 2000 at Sodankylä and Jokioinen, respectively. A SL501A radiometer, measuring erythemally-weighted UV radiation, and a CM11 pyranometer, measuring global radiation, have been set up next to the Brewers. The measurements are synchronized, so that a reading is recorded each time a wavelength is mea-

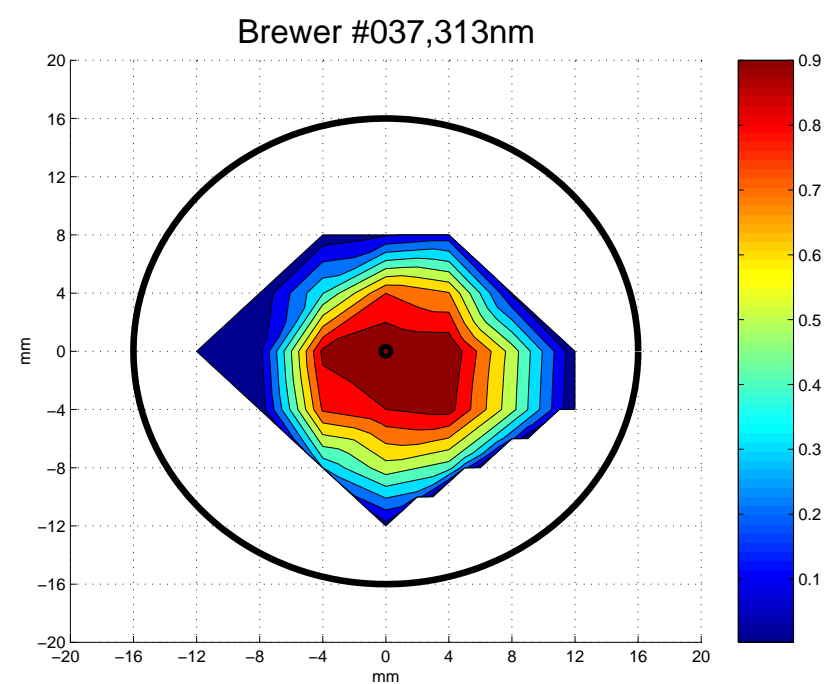

Fig. 1. The response from different parts of the diffuser of Brewer \#037 at $313 \mathrm{~nm}$. The areas around the centre are the most sensitive.

sured with the Brewer. Broadband measurements can be used to monitor the stability of the sky conditions during a Brewer scan.

\section{Characterizations}

In order to make reliable measurements and to process the data correctly, laboratory characterizations of the instruments are needed. In the following subsections we present the characterizations that have been made for the FMI Brewers.

\subsection{Angular response}

The signal of a spectroradiometer should be proportional to the cosine of the angle $\theta$ between the direction of the incident radiation and the normal of the radiometer's diffuser. The deviation from this ideal response is called the cosine error. In order to be able to correct the data, the angular response of the instrument has to be characterized. The angular response of Brewer \#037 has been characterized in 1996, 2000 and 2003, and Brewer \#107 in 1996 and 2003 (Bais et al., 2005). The angular responses used in the actual data processing are those derived from the characterizations of 2000 and 1996 for the Brewers \#037 and \#107, respectively.

The incident angle of radiation should be measured with respect to the most sensitive part of the diffuser. For the FMI Brewers, the diffusers were characterized following W. Josefsson (personal communication). The quartz dome of the diffuser was removed, in order to quantify the properties of the diffuser alone. A black paper screen with a $4 \mathrm{~mm}$ hole was moved on a grid of $4 \mathrm{~mm}$ while measuring a calibration lamp. The results for Brewer \#037 at $313 \mathrm{~nm}$ is presented in Fig. 1, where it is seen that the most sensitive parts are 


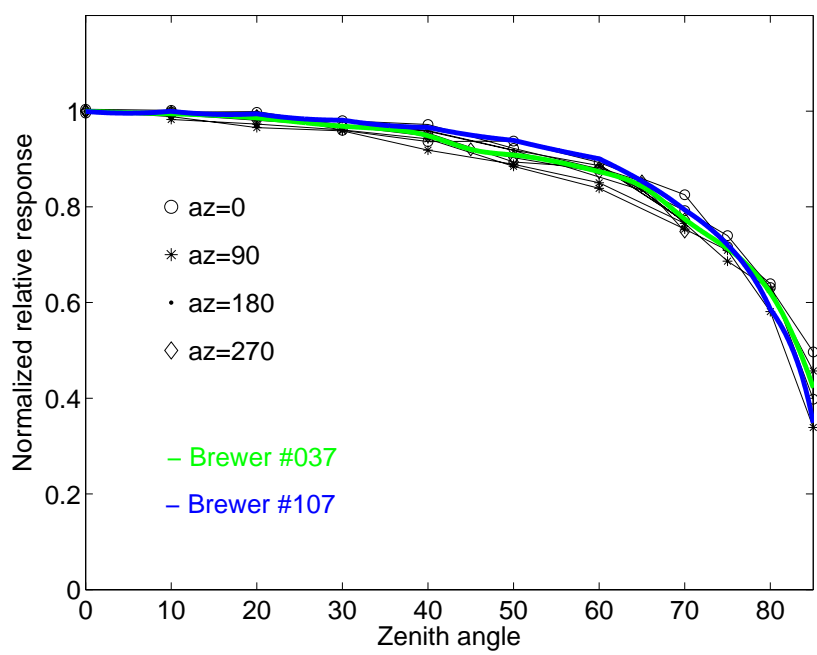

Fig. 2. The characterization of the cosine response of Brewer $\# 037$ at four azimuth angles (north $=0^{\circ}$, east $=90^{\circ}$, south $=180^{\circ}$, west $=270^{\circ}$ ) in steps of $5^{\circ}$ or $10^{\circ}$. The normalized relative response is shown. The averaged and interpolated normalized relative response is also shown for Brewer \#107 (blue line) and Brewer \#037 (green line).

situated, as expected, more or less around the centre of the diffuser. The result for Brewer \#107 was similar, except that the most sensitive part was even more centred.

The angular response measurements were performed in the dark-room at constant temperature. A $1000 \mathrm{~W}$ DXW, a vertical beam lamp, was mounted in a holder, which could be moved to different angles. Zenith angles from $0^{\circ}$ up to $85^{\circ}$ and back to $0^{\circ}$, in steps of $5^{\circ}$ or $10^{\circ}$, were measured at four azimuth angles (north $=0^{\circ}$, east $=90^{\circ}$, south $=180^{\circ}$, west $=270^{\circ}$ ). The angular responses obtained, normalized to the ideal cosine response, are shown in Fig. 2 for the four azimuth angles for Brewer \#037. The results for Brewer \#107 were comparable to the results of Brewer \#037, with slightly less steep curves. The cosine error of the direct beam exceeded $10 \%$ at an SZA higher than $50^{\circ}$. The results of both Brewers showed no dependency on the azimuth angles, and the final angular response was calculated by taking the average of the azimuths. The final normalized and interpolated angular responses of both Brewers are also shown in Fig. 2 .

\subsection{Slit function and wavelength calibration}

The entrance and exit apertures of a monochromator have finite widths. As a consequence, not only photons with the desired wavelength $\lambda_{0}$ pass through the monochromator, but also those with wavelengths within a certain interval around $\lambda_{0}$. When the monochromator is set to a fixed wavelength $\lambda_{0}$, its transmittance, as a function of wavelength, is called the slit function $f(\lambda)$. The width of the slit function is of-

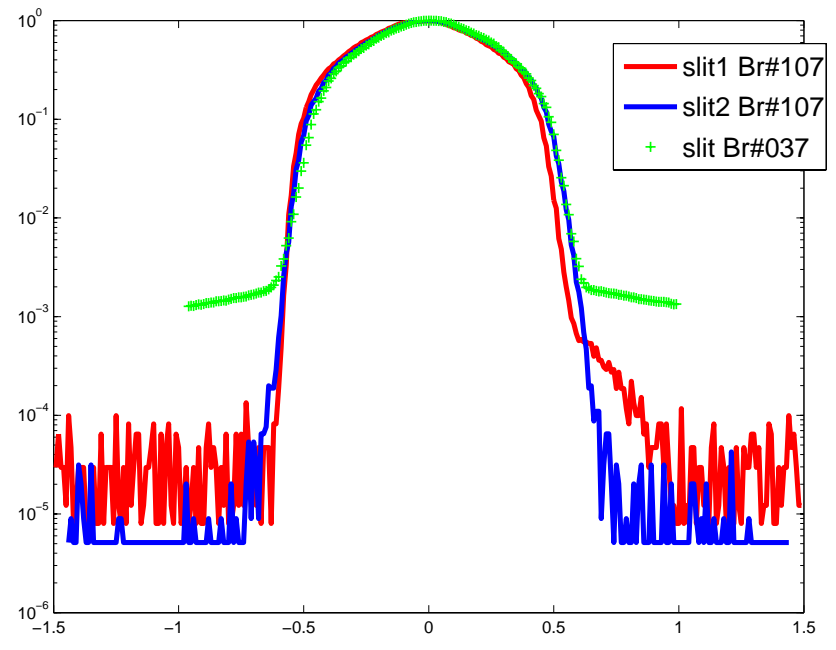

Fig. 3. The slit functions of the Brewers \#037 and \#107.

ten quantified by the full width of the function at half of its maximum (FWHM).

The slit functions for the spectrophotometers at Sodankylä and Jokioinen were characterized for the first time during the intercomparison at Izaña in 1996 (Kyrö, 1997). They were determined using the $\mathrm{HeCd}$-laser line at $325.029 \mathrm{~nm}$ as a source of monochromatic light. In addition, the slit function of Brewer \#107 was measured twice in 1997 immediately before and after the realignment of the monochromator, and once again in 2002. The repeated characterizations confirmed the stability of the slit function between the years 1996 and 1997, the expected change in 1997, and another period of stability thereafter. Figure 3 shows the measured slit functions of both Brewers. For Brewer \#107, the slit function "slit1" was used before day 114 in 1997, while "slit2" was used from that day onwards.

The two Brewers have symmetrical and nearly identical slit functions down to about $10^{-3}$ of the maximum of the signal. Below that level, the internal stray light in the Mk II Brewer at Sodankylä can be seen as persistent noise that is handled as described in Ch.5.2. In the Mk III instrument at Jokioinen, the stray light level is about two decades lower. The FWHM for the Brewers \#037 and \#107 are 0.56 and 0.59 , respectively.

The relation between the actual wavelength $(L)$ during the scan of an irradiance spectrum and the position $\left(M_{1}\right)$ of the micrometer turning the grating in the first monochromator is given by the equation

$L=d_{1}+d_{2} M_{1}+d_{3} M_{1}^{2}$,

where $d_{1}, d_{2}$, and $d_{3}$ are the so-called dispersion coefficients. The determination of these coefficients is an essential part of each annual maintenance. This work utilizes the emission lines of spectral discharge lamps, usually those of mercury 
and cadmium. The correct positioning of the grating is physically checked on every UV scan using the $296.7 \mathrm{~nm}$ line of an internal mercury lamp.

In the case of Brewer \#107, the year-to-year change needed in the calibration has always been equivalent to a very small, i.e., from zero to $0.1 \mathrm{~nm}$, adjustment in the wavelength scale. During the last five years there has been no need for any change in Brewer \#107, which indicates a good wavelength stability.

\subsection{Temperature dependence}

Brewer spectrophotometers are provided with a heating element maintaining the internal temperature above approx. $+8^{\circ} \mathrm{C}$ under all conditions. However, the instrument is not temperature stabilized. According to, e.g., Cappellani and Kochler (1999) and Weatherhead et al. (2001), Brewer measurements have a temperature dependence, which may be attributable to temperature dependences in the photomultiplier tube itself and in the filters in front of the photomultiplier. Ylianttila and Schreder (2005) have discussed the temperature sensitivity of teflon diffusers.

In 1998, in order to determine the temperature dependence of the Brewers \#037 and \#107, the routine lamp irradiance measurements were analyzed with respect to temperature. The study indicated temperature dependencies that could not be overlooked. The dependencies were subsequently characterized for both instruments by on-site laboratory measurements of $1000 \mathrm{~W}$ working standard lamps from Optronics Inc.

The procedure for the characterization measurements was as follows: The Brewers were heated and cooled using an air-blower system built for the purpose. Each scan was made after the temperatures and gradients inside the instrument had fully stabilized. The range of the internal temperatures covered values from 15.3 to $47.6^{\circ} \mathrm{C}$ and 14.8 to $45.2^{\circ} \mathrm{C}$ for $\# 107$ and \#037, respectively. Unfortunately, the available equipment did not allow cooling the system to any lower temperatures. The temperature of the dark room was stabilized at $23^{\circ} \mathrm{C}$.

The results suggested a linear dependence between the internal temperature and the photon counts per cycle; this dependence can be used for correcting the data. A linear model relating the irradiance and the temperature was formulated as follows:

$I(\lambda)=I 0(\lambda) *(1+c(\lambda) * d T)$

Here, $d T=T-T 0$ is the temperature difference between the Brewer's internal temperature $T$ and the reference temperature $T 0=23^{\circ} \mathrm{C} ; I 0=I(T 0)$ is the reference irradiance (in counts/cycle); $I$ is the measured irradiance (in counts/cycle); and $c(\lambda)$ is the temperature dependence factor (in units of $\left.1 /{ }^{\circ} \mathrm{C}\right)$. The temperature dependence factors obtained by linear regression for each wavelength are shown in Fig. 4. Also shown are the fits (a polynomial for \#107 and a two-piece

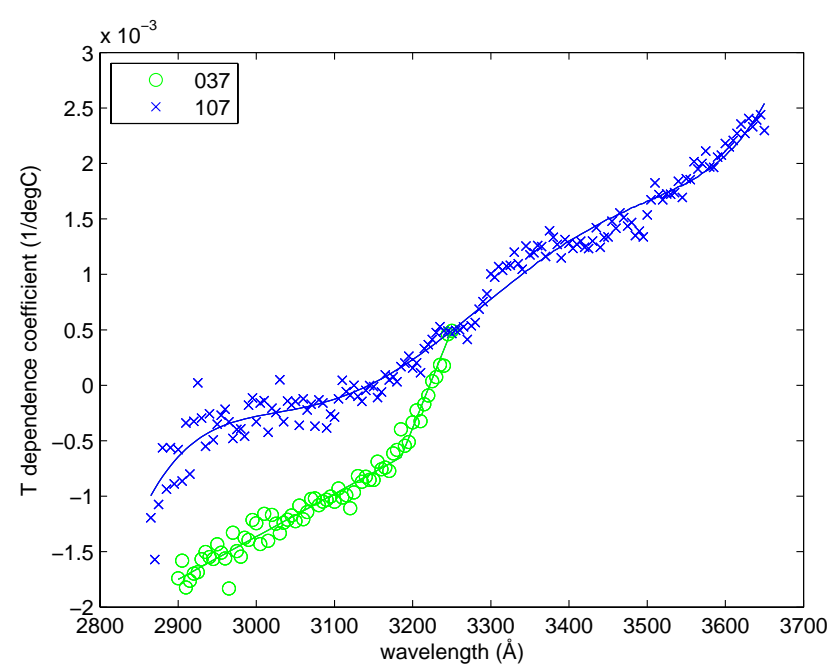

Fig. 4. Temperature dependence factors obtained for Brewer \#107 (green crosses) and Brewer \#037 (blue circles).

linear for \#037) that are performed in order to smooth the ripples in the curves.

Garane et al. (2006) presented a temperature characterization methodology that has a few differences compared to ours. They performed continuous scans with Brewers brought into and warming up in the laboratory, whereas in our measurements scans were taken after the Brewers had stabilized to a given temperature. The temperature correction factor for a double monochromator derived by Garane et al. (2006) exhibited no wavelength dependence, in contrast to our characterization measurements, in which wavelength dependences for both the single and the double monochromator were detected. It is not yet known whether this difference is due to the differences in the measurement procedures or to inherent variations between the individual Brewer instruments discovered by, e.g., Weatherhead et al. (2001).

\section{Long-term spectral responsivity}

The long-term spectral responsivities of both Brewers have been calculated for the whole period of measurements. The objective has been to obtain instrument spectral responsivity time series based on one specific irradiance scale for the whole measurement period. A set of lamp measurements during the period are used. The lamp measurements are made at both sites on the roof and in the laboratory dark-room, and the data are corrected to the reference temperature. Before the years 1998 and 1997, at Sodankylä and Jokioinen, respectively, only $50 \mathrm{~W}$ lamp measurements made on the roof were available. Thereafter mainly laboratory measurements of $1000 \mathrm{~W}$ lamps have been used. The process involves the use of several lamps throughout the whole period, and the 

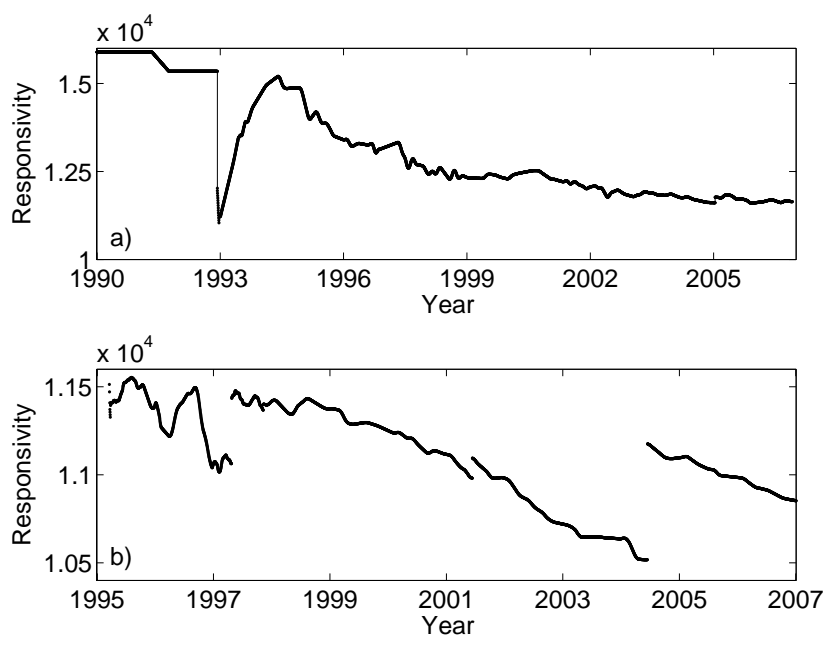

Fig. 5. The responsivity time series 1990-2006 and 1995-2006 for the Brewers (a) \#037 and (b) \#107, respectively, at $305 \mathrm{~nm}$.

way individual lamps are used is slightly different for the two Brewers; both methods are presented here.

Firstly, the lamp measurements are quality-checked manually. Secondly, the chosen irradiance scale is transferred from the primary standard to the working standard and working lamps. Thereafter, any possible drifts in the lamps are detected by comparing the time series of all lamp measurements against each other. If a drift is detected, measurements with that lamp are either excluded or, if possible, re-calibrated with the help of the other lamps. The irradiance scale used in this analysis is provided by the Helsinki University of Technology (HUT). The primary standards of both Brewers are calibrated on average once a year at the HUT, which is an accredited national Standard Laboratory (Kübarsepp et al., 2000).

Once the set of trusted lamp measurements has been compiled, calculation of the instrument spectral responsivity is possible for each measurement time of an individual lamp and for each wavelength. In the case of Brewer \#107, a linear time interpolation is thereafter performed for each lamp separately to give a continuous spectral responsivity time series based on that lamp. Thereafter all the spectral responsivity time series are averaged, and finally a running average is calculated using a \pm 15 day window, which smooths out small-scale time variations from the final product. However, in the case of Brewer \#037, all the available lamp measurements during a given day are first averaged, and thereafter time-interpolated and smoothed. The choice between the order in time-interpolating and averaging individual lamps is subjective, and depends on the number of trusted lamps, on the frequency of laboratory calibrations, and on the desired level of small-scale features in the final spectral responsivity time series.
Figure 5 shows the $305 \mathrm{~nm}$ responsivity time series for the Brewers \#037 and \#107. The sudden severe drop in 1993 in the responsivity of Brewer \#037 is due to the accidental burning of a heating element inside the instrument box. After this accident, the responsivity rose to almost it's previous level after which ageing has occurred, showing as a downward drift of a couple of percent per year. Approximately the same drift is observed for Brewer \#107. The points of discontinuity in the responsivity time series denote occasions of instrument maintenance and repair on which the instrument characteristics have changed. Drifts of the same order of magnitude are also observed in Garane et al. (2006). They report a decrease in the spectral responsivity at $320 \pm 5 \mathrm{~nm}$ of around $3 \%$ per year for both the single and double monochromator Brewer spectroradiometers of Thessaloniki. They suggest that the drift is due to an aging effect of the different optical components of the instrument, including the diffuser.

During our work, we have compared spectral responsivities produced using only $50 \mathrm{~W}$ working lamps and only using $1000 \mathrm{~W}$ lamps. This was important, as at the beginning of the time series we made only $50 \mathrm{~W}$ lamp measurements, and the question arose, how well we can trust these measurements? Nowadays, each time the Brewer measures $1000 \mathrm{~W}$ lamps in the laboratory dark-room, $50 \mathrm{~W}$ lamps are also measured. Additionally, between laboratory measurements, $50 \mathrm{~W}$ lamps are measured on the roof. We can therefore produce two different spectral responsivity time series: one using only the $1000 \mathrm{~W}$ lamps and one using only the $50 \mathrm{~W}$ lamps. In both time series, the irradiance scale has been transfered from the primary standard $1000 \mathrm{~W}$ lamp, and the spectral responsivity has been corrected to the reference temperature. These two spectral responsivity time series follow each other within the measurement uncertainties, and give us confidence that the whole time series is homogenized, even though only $50 \mathrm{~W}$ lamps were used at the begining.

\section{Data processing}

In the previous section, we have described the laboratory characterizations performed for our spectrophotometers. In this section the known errors are now corrected using these laboratory characterizations, using a theoretical approach or using a combination of these two.

The raw data is processed into irradiances using a Perl language program called spede.pl. It is based on the Qbasic program, that was released by the manufacturer of the Brewer spectrophotometers (SCI-TEC). Some additional corrections, e.g., the cosine correction, the spike correction and the temperature correction have been implemented within the FMI. During the processing of the data, some check values, e.g., for an impossible high UV index, are calculated on the fly, in order to warn for suspicious measurements. 


\subsection{Noise spikes}

The first step is to remove noise spikes from the raw data. By spikes we refer to an anomalous number of counts recorded in one wavelength channel causing a peak upwards or downwards that does not originate from the true radiation signal (Meinander et al., 2003). The origin of the spikes is not fully understood, but the spectrum can be corrected. The spike correction algorithm is based on Meinander et al. (2003), where a statistical method is used to identify the noise spikes in the Brewer UV spectra. In order to work both for small and large count values in the raw data, the method is based on differences in relative changes in the spectra.

For the correction, two main parts have to be done beforehand. First a clear sky reference spectrum is needed. For Sodankylä and Jokioinen, two years of cloud-free data were used for calculating an average clear sky spectrum. Secondly, a statistical standard deviation file was computed, based on a large (two-year) data set.

Next, the spectral ratios of raw counts $(C)$ divided by the reference $(R)$ are computed. These are termed Ratios. The differences of these Ratios between the neighbouring channels $\lambda$ and $\lambda-i$, where $i$ denotes the Brewer spectrum step, are calculated. These differences are termed Dratios, as given by

$$
\operatorname{Dratio}(\lambda)=\frac{C(\lambda)}{R(\lambda)}-\frac{C(\lambda-i)}{R(\lambda-i)}
$$

Dratios are then compared with the chosen confidence level.

This means that a peak is detected if the signal in the first channel goes up and that in the next channel down, or vice versa. Other kinds of peaky features are expected to be due to changes in the cloud conditions. In addition, only relatively large spikes are considered, i.e., the ratio of counts divided by the corrected counts exceeds 1.5 or is less than 0.5 .

The new corrected value for the removed peak is calculated as the average of the Ratios of the neighbouring channels multiplied by the reference spectrum value at that channel, as given by

$C(\lambda)$ corrected $=0.5 *\left(\frac{C(\lambda-i)}{R(\lambda-i)}+\frac{C(\lambda+i)}{R(\lambda+i)}\right) * R(\lambda)$.

In this way the shape and the fine structure of the spectral features are preserved.

\subsection{Dark current, dead time and stray light}

The dark current is the response exhibited by the photomultiplier during periods when it is not actively being exposed to light. The dark current is recorded before each scan. Raw count values for further data processing are obtained by subtracting the measured dark current from the measured counts in a function including the number of cycles and the integration time.
The dead time is the time after each light exposure, during which the photomultiplier would not be able to record another exposure if it were to happen. The dead time of the Brewer is regularly recorded, and daily values are saved in a dead time history file. Typical dead time values for both Brewers are 30-40 ns. A dead time correction to the raw counts is performed using an iteration of an exponential function including the number of counts and the dead time values.

Stray light consists of radiation at wavelengths outside the wavelength range of the slit function that is detected inside the range expected. This is a special problem inherent in single monochromator spectroradiometers. Brewer \#107 is a double monochromator, in which the amount of stray light passing into the detector is minimal. The average of counts at wavelengths shorter than $292 \mathrm{~nm}$ is calculated. This average value is subtracted from the count values at each wavelength of the spectrum. Since Brewer \#037 is a single monochromator, stray light disturbs measurements up to around $305 \mathrm{~nm}$ (Bais et al., 1996). For this Brewer, signals at wavelengths shorter than $293 \mathrm{~nm}$ are considered as stray light, and are subtracted from longer wavelengths.

\subsection{Temperature}

The temperature dependencies of the Brewers are corrected using the temperature dependence coefficients derived from the characterization measurements described in Sect. 3.3. Each scan is normalized to the reference temperature by computing $\mathrm{I} O(\lambda)$ on the basis of Eq. (2). The procedure yields a time series of irradiance scans (in units of counts/cycle) normalized to the same reference (laboratory) temperature for which the response of the instrument has been derived $\left(23^{\circ} \mathrm{C}\right)$. The procedure differs from that presented by Garane et al. (2006) in the selection of the reference temperature. In our method, the reference is constant, whereas in the method presented by Garane et al. (2006), the reference is the temperature of the absolute calibration valid for the period.

\subsection{Cosine error}

Several papers have been written about methods for the cosine correction of radiometers (Landelius and Josefsson, 2000; Bais et al., 1998; Feister et al., 1997; Seckmeyer and Bernhard, 1993). They differ mostly in their way of handling the radiation distribution of the sky. The FMI method is shortly described here.

If $F$ denotes the actual and $F^{\prime}$ the measured irradiance, we can define the correction factor for the angular response of a spectroradiometer $\left(f_{\text {glob }}\right)$ for a particular global irradiance measurement as 
$f_{\text {glob }}=\frac{F_{\text {glob }}}{F_{\text {glob }}^{\prime}}=\frac{F_{\text {diff }}+F_{\text {dir }}}{F_{\text {diff }}^{\prime}+F_{\text {dir }}^{\prime}}$,

where the subscripts glob, diff, and dir correspond to global irradiance and its diffuse and direct components, respectively.

Equation (5) can be rewritten as

$f_{\mathrm{glob}}=\frac{\left(F_{\mathrm{dir}} / F_{\mathrm{diff}}+1\right)}{\left(F_{\mathrm{dir}}^{\prime} / F_{\mathrm{dir}} * F_{\mathrm{dir}} / F_{\mathrm{diff}}+F_{\mathrm{diff}}^{\prime} / F_{\mathrm{diff}}\right)}$.

Equation (6) suggests that in order to obtain the cosine correction factor, three components are needed:

1) $F_{\text {dir }}^{\prime} / F_{\text {dir }}$, the ratio between the measured and actual direct irradiance, i.e., the direct cosine error,

2) $F_{\text {diff }}^{\prime} / F_{\text {diff }}$, the ratio between the measured and actual diffuse irradiance, i.e., the diffuse cosine error,

and 3) $F_{\text {dir }} / F_{\text {diff }}$, the ratio between the actual direct and diffuse irradiance.

The ratio between the measured and actual direct irradiance can be expressed as the ratio of the angular response of the diffuser $(\mathrm{C}(\theta, \lambda))$ and the cosine of the solar zenith angle $(\theta)$,

$\frac{F_{\mathrm{dir}}^{\prime}}{F_{\mathrm{dir}}}=\frac{C(\theta, \lambda)}{\cos (\theta)}$.

The ratio between the measured and actual diffuse radiation is

$\frac{F_{\text {diff }}^{\prime}}{F_{\text {diff }}}=\frac{\int L(\theta, \phi, \lambda) * C(\theta, \lambda) d \Omega}{\int L(\theta, \phi, \lambda) * \cos (\theta) d \Omega}$,

where the spectral radiance $L(\theta)$ is integrated over the upper hemisphere, $\theta$ is the zenith angle and $\phi$ the azimuth angle. In general, the exact sky radiance distribution $(L(\theta, \phi, \lambda))$ is not known. By assuming isotropic diffuse radiation, however, Eq. (8) can be simplified to

$\frac{F_{\text {diff }}^{\prime}}{F_{\text {diff }}}=\frac{\int C(\theta, \lambda) d \Omega}{\pi}$.

In our method, the ratio between the actual direct and diffuse irradiance, $F_{\mathrm{dir}} / F_{\text {diff }}$, is obtained using a radiative transfer model. The LibRadtran package and UVspec disort version (http://www.libradtran.org) (Mayer and Kylling, 2005) was used in the following way: Assuming the UV irradiance can be expressed as a function of wavelength, solar zenith angle, cloud optical depth, ozone absorption, aerosols and albedo, a six-dimensional lookup table can be constructed. Using the lookup table and knowing the irradiance at each wavelength from the measured Brewer spectrum, the cloud optical depth, $\tau_{\text {cloud }}(\lambda)$, can be found as a function of wavelength. Further details of this approach to estimate the cloud optical depth can be found in Arola et al. (2003b). Once $\tau_{\text {cloud }}(\lambda)$ is found, the radiative transfer model is used to derive the direct-to-diffuse ratio as a function of wavelength.
Once $F_{\mathrm{dir}} / F_{\mathrm{diff}}$ is obtained and the angular response of the diffuser, $C(s z a, \lambda)$ is known, Eq. (6) can be used to estimate the cosine correction factor for each wavelength. Inserting the angular response of the Brewers at Sodankylä and Jokioinen into Eq. (9), and assuming the diffuse to be radiation isotropic, the ratios between measured and actual diffuse irradiance are 0.90 and 0.91 , respectively. This means that, when there is no direct light coming into the instrument's diffuser, the errors in the measurements due to the non-ideal angular response can be as much as $10 \%$ and $9 \%$ for Sodankylä and Jokioinen, respectively. This value is modified in the presence of direct irradiance, and its change depends on the ratio between the actual direct and diffuse radiation. The actual cosine correction factors of the Brewers at Sodankylä and Jokioinen can vary between $1.08-1.13$ and $1.08-1.12$, respectively, depending on the wavelength.

Bais et al. (2005) have described the cosine characterization of several spectroradiometers using a portable device for characterizing the angular responses. Among the instruments, the two Finnish Brewers were characterized as well. The results show angular response errors in the diffuse irradiance, assuming isotropic radiation, of $10.4 \pm 3 \%(1 \sigma)$ and $8.0 \pm 3.1 \%(1 \sigma)$ for the Brewer \#037 and Brewer \#107, respectively. The results are consistent with our results within the measurement uncertainties. Garane et al. (2006) report mean cosine correction factors of $7 \pm 1.5 \%(1 \sigma)$ and $11 \pm 2 \%$ $(1 \sigma)$ for the single and double monochromator Brewers of Thessaloniki, respectively.

\subsection{Wavelength alignment}

Because of the strong increase of the solar spectrum with wavelength in the UV-B range, even small errors in the wavelength alignment of a spectroradiometer lead to significant errors in measured spectral irradiance. Brewer spectrophotometers are typically assumed to have only minor problems with wavelength alignment. The need to perform a wavelength shift correction is therefore not seen as critical. This is indeed the case for most Brewers, including Brewer \#107. In such cases, the wavelength error is randomly spread around the average wavelength error.

In the case of Brewer \#037, Arola et al. (2003b) found that a stepwise change in the wavelength alignment had occurred between 1993 and 1994. The typical value for the wavelength shift before 1994 was $-0.06 \mathrm{~nm}$, and $0.01 \mathrm{~nm}$ thereafter. If this wavelength error had not been corrected, an error of several percent could have been introduced in a long-term change analysis of UV spectra.

The current data processing includes a wavelength shift correction using the SHICRIVM wavelength shift correction package described in Slaper et al. (1995). Spectra transfered to the EUVDB database, for example, have been corrected for possible wavelength shift. 
Table 2. Intercomparison campaigns in which the FMI Brewers have participated.

\begin{tabular}{|c|c|c|c|c|}
\hline Year & Campaign & Place & \#037 & \#107 \\
\hline 1993 & NOGIC-93 Nordic comp. & Izaña, Spain & $\mathrm{x}$ & \\
\hline 1995 & CAMSSUM European comp. & Ispra, Italy & & $\mathrm{x}$ \\
\hline 1996 & NOGIC-96 Nordic comp. & Izaña, Spain & $\mathrm{x}$ & $\mathrm{x}$ \\
\hline 1997 & SUSPEN European comp. & Nea Mihaniona, Greece & & $\mathrm{x}$ \\
\hline 2000 & NOGIC-00 Nordic comp. & Tylösand, Sweden & $\mathrm{x}$ & $\mathrm{x}$ \\
\hline 2002 & QASUME Core group of Europe & Ispra, Italy & & $\mathrm{x}$ \\
\hline 2002 & QASUME portable reference visit & Jokioinen & & $\mathrm{x}$ \\
\hline 2003 & QASUME portable reference visit & Jokioinen and Sodankylä & $\mathrm{x}$ & $\mathrm{x}$ \\
\hline 2005 & QASUME portable reference and Iberonesian network comp. & Huelva, Spain & & $\mathrm{x}$ \\
\hline 2007 & QASUME portable reference visit & Jokioinen and Sodankylä & $\mathrm{x}$ & $\mathrm{x}$ \\
\hline
\end{tabular}

\section{Quality assessment}

Following Webb et al. (2003), the quality assessment of an instrument can be done by comparing the instrument to other independent instruments measuring the same quantities. In this section, we review the results of intercomparison campaigns and comparison with the portable reference spectroradiometer QASUME (Quality Assurance of Spectral Ultraviolet Measurements in Europe) (Bais et al., 2003). For quality assurance purposes the measurements are also compared with reconstructed UV dose rates. The flagging reports of the spectra transferred to the European UV Data Base (EUVDB) are also discussed.

\subsection{Intercomparison campaigns}

Both Brewer spectrophotometers of the FMI have participated in several international UV spectroradiometer comparisons (Koskela, 1994; Kjeldstad et al., 1997; Gardiner and Kirsch, 1997; Bais et al., 2001; Meinander et al., 2003; Thorseth et al., 2002). Table 2 shows in detail the year of the campaign, the location and the Brewer that has participated. Brewer \#037 has mainly participated in the Nordic comparisons and has been the host for two portable reference spectroradiometer QASUME visits, whereas Brewer \#107 has travelled successfully around Europe. This instrument took part in the Ispra comparison in 2002, to which were invited six spectroradiometers that had performed consistently in previous intercomparisons. Besides the intercomparison campaigns with several instruments, smaller intercomparison campaigns have been organized. A regular comparison is done on the yearly visit of the reference Brewer \#017 of the International Ozone Services (IOS). During these visits, both UV and ozone measurements are compared, and the instruments are checked and maintained, if necessary. National comparisons have also been performed during many of these visits.

When interpreting the results of the intercomparison campaigns, we need to keep in mind that especially the results obtained in the earliest campaigns represent the situation pre-

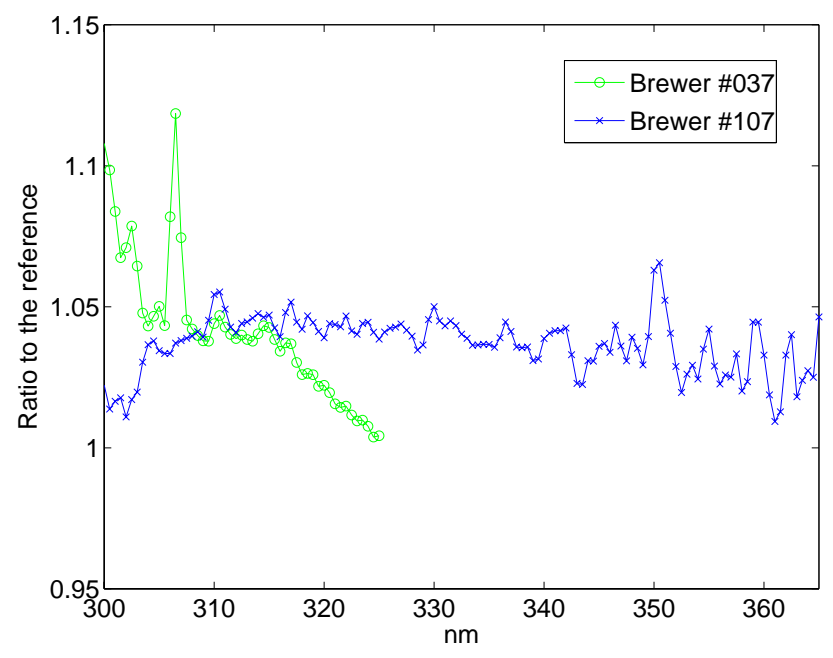

Fig. 6. The ratios (Brewer/Reference) of daily sums of irradiances for the Brewers \#037 (green) and \#107 (blue) during the NOGIC2000 intercomparison campaign for day number 164 .

vailing at that time, and that the data can nowadays be reanalyzed using different methods and knowledge. In those first intercomparisons, almost no instrument had correction for the cosine error. Also, the intercomparisons were concentrated on clear sky weather.

Every campaign has been a good step to improve the measurements. Regarding the FMI Brewers, the NOGIC-00 campaign was the first, in which the data processing procedures presented in this paper were in use. In that campaign, the cosine correction and temperature correction procedures where used for the first time. An example of one day's measurements (06:00 UTC-20:00 UTC) compared to the reference spectra is shown in Fig. 6. The plots are ratios of the daily sums of irradiances measured with the Brewers to the calculated reference daily sums. The measurements were processed using the SHICrivm QA/QC software package (Slaper et al., 1995), and the reference spectra were 

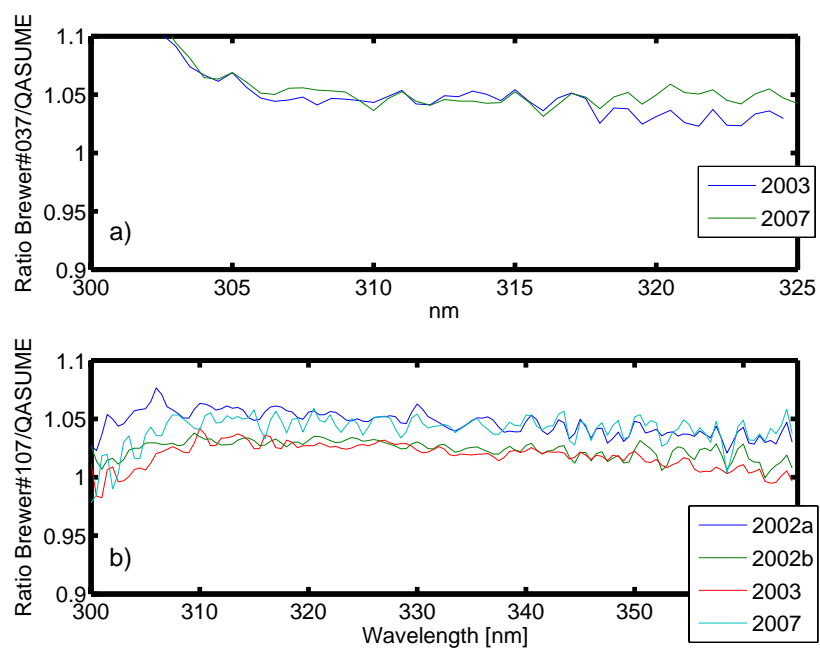

Fig. 7. The results of the comparisons between (a) Brewer \#037, (b) Brewer \#107 and the portable reference spectroradiometer QASUME.

calculated following Slaper and Koskela (1997). From the figure, it can be seen that compared to the reference spectra, Brewer \#037 was within $\pm 5 \%$ at wavelengths longer than $305 \mathrm{~nm}$ and Brewer \#107 was within $\pm 5 \%$ at most of the wavelengths. Individual spikes can be due to changing cloud conditions at a single moment. The observed downward drift observed at wavelengths longer than $317 \mathrm{~nm}$ for Brewer \#037 was due to problems with the irradiance scale of one calibration lamp. The lamp was recalibrated after the campaign.

From previous intercomparisons, the most important result is that the ratio to the reference was stable during the comparison days. In the NOGIC-96 intercomparison, for example, the standard deviation of the ratio of the measured dose rate to that of the reference was $1-2 \%$ for both instruments. The other important result is that all measurements starting from the beginning of the time series are appropriate after applying all known corrections to the data.

\subsection{QASUME reference}

The portable reference spectroradiometer QASUME from Physikalisch-Meteorologisches Observatorium Davos, World radiation Center (PMOD/WRC) is a Bentham spectroradiometer, whose irradiance scale is traceable to the primary standard of the Physikalisch-Technische Bundesanstalt (PTB), Germany, through transfer standard lamps (Gröbner and Sperfeld, 2005). It can be seen as the "European standard spectroradiometer", and the irradiance scale is assumed to be stable over the years. As spectroradiometers are challenging instruments for travelling, this gives a good opportunity for checking the performance of a site spectroradiometer without travelling.

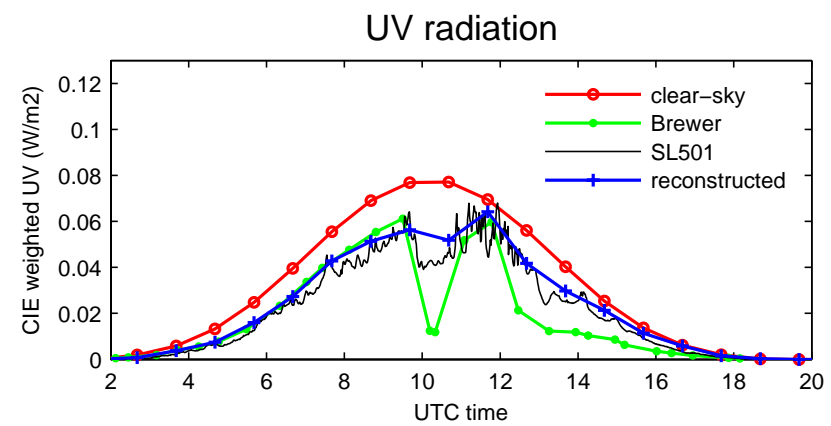

Global radiation

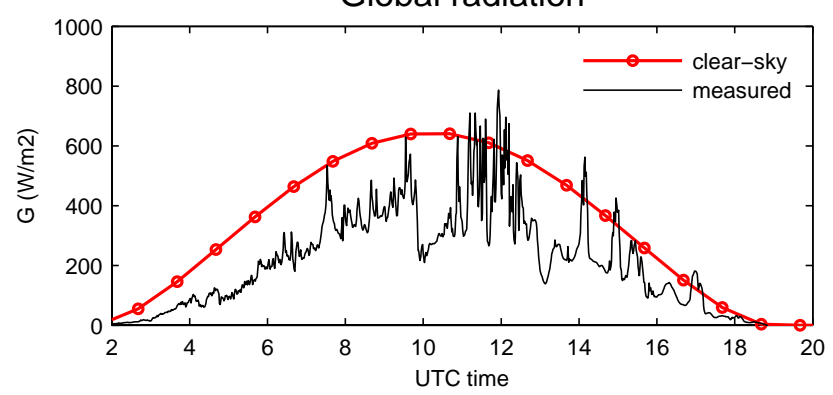

Fig. 8. Brewer \#037 UV dose rates plotted together with modelled clear sky UV dose rates, reconstructed dose rates, SL501A dose rates, modelled clear sky global radiation and CM-11 pyranometer global radiation measurements at Sodankylä for 29 April 2001.

The portable reference spectroradiometer QASUME has visited Jokioinen and Sodankylä in 2003 and 2007. In addition to this, the instrument visited Jokioinen during the first experimental year, in 2002. The Jokioinen Brewer \#107 was also part of the core group, and participated in the starting comparison of the QASUME project in 2002, in Ispra, Italy (Gröbner et al., 2005). The protocol of each site visit included measurements of the spectral solar irradiance, which were performed every half-an-hour from the morning to the evening. Synchronized solar spectra were obtained in the range of the site spectroradiometer, every $0.5 \mathrm{~nm}$, with a wavelength increment every $3 \mathrm{~s}$. The solar spectra were converted to a common wavelength scale and to a nominal resolution of $1 \mathrm{~nm}$ using the SHICRivm software package. A detailed description of the measurement procedure is published in Gröbner et al. (2005).

A summary of the results is shown in Fig. 7 for both the Brewers. The mean ratio to the QASUME reference for SZA smaller than $75^{\circ}$ are shown for all comparison years. For Brewer \#037, the results of both comparisons, in 2003 and 2007, are near each other. A difference of around 5\% can be seen in wavelengths longer than $305 \mathrm{~nm}$. At shorter wavelengths, the typical single monochromator stray light problem disturbs the readings, and those wavelengths need to be rejected.The small downward shift at longer wavelengths in 2003 may be due to problems with a single calibration lamp. 
For Brewer \#107, a difference of around 4-5\% was observed in 2002 and 2007, at Ispra and Jokioinen, respectively. At Jokioinen in 2002 and 2003 the mean difference was around $2 \%$. These results show very good agreement within the measurement uncertainties of spectral measurements and demonstrate the good stability of the instrument. As the irradiance scale of the FMI Brewers is traceable to the HUT, and that of QASUME to PTB, some differences in the scale are possible (Gröbner et al., 2002). The stable difference between the instruments over all wavelengths also supports the theory of differences in the irradiance scale. At Jokioinen, in 2007, using laboratory lamp measurements, the difference in the irradiance scale was found to be $3 \%$. This leaves only $2 \%$ of the differences to be explained, which can be considered as a very good results in the challenging field of measuring UV wavelength spectra.

\subsection{Comparison with reconstructed UV}

For quality assurance purposes, the UV spectra are processed to give erythemally-weighted UV dose rates that are compared with reconstructed UV dose rates. The reconstruction of the UV dose rates is based on the method described in Lindfors et al. (2007). The method uses pyranometer measurements to quantify the influence of clouds. A radiative transfer model is used to reproduce the UV dose rates using an appropriate cloud modification factor.

For quality assurance purposes figures are plotted showing the reconstructed erythemally-weighted UV dose rates, the measured UV dose rates, the modelled clear sky UV dose rates, and the modelled clear-sky global radiation and global radiation measured with a CM-11-type pyranometer. Figure 8 shows an example of a suspicious measurement day, the 29th of April 2001 at Sodankylä. One-minute dose rates measured with a nearby SL501A radiometer are also plotted. Both the modelled values and the SL501A data behaviour differ from that of the Brewer measurement at around 10:00 UTC. The Brewer seems to have measured values that are too low.

One need to be careful, when interpreting figures like Fig. 8. As the modelled data is presented as a one-hour average, the data represent the average situation during that hour. The Brewer data, on the other hand, represent the sky conditions over some minutes, which means that differences from the model are obviously possible, e.g. large changes in cloudiness can be observed on a time-scale of minutes, leading to high variations in the UV radiation. A feature like that shown in Fig. 8 could be due to a sudden rain shower, heavy clouds, malfunction of the instrument, a local shadow on the diffuser caused e.g., by a person walking by, cleaning of the dome or for some other unknown reason. Ancillary measurements are often needed in order to find out if the feature is real or not. In this specific case, the SL501A erythemal UV dose rates confirm the doubt that something is wrong with the Brewer measurement. The most probable reason
Table 3. Summary of the all Sodankylä and Jokioinen quality flags in the EUVDB database.

\begin{tabular}{lccccr}
\hline Sodankylä & GREEN & YELLOW & RED & GREY & BLACK \\
\hline shift1 & $97.98 \%$ & $0.00 \%$ & $0.00 \%$ & $2.02 \%$ & $0.00 \%$ \\
start irr & $99.61 \%$ & $0.13 \%$ & $0.08 \%$ & $0.07 \%$ & $0.11 \%$ \\
spike+shape & $94.87 \%$ & $4.20 \%$ & $0.69 \%$ & $0.08 \%$ & $0.16 \%$ \\
\hline Jokioinen & GREEN & YELLOW & RED & GREY & BLACK \\
\hline shift1 & $99.12 \%$ & $0.60 \%$ & $0.00 \%$ & $0.27 \%$ & $0.00 \%$ \\
shift2 & $99.83 \%$ & $0.00 \%$ & $0.00 \%$ & $0.17 \%$ & $0.00 \%$ \\
start irr & $99.86 \%$ & $0.05 \%$ & $0.04 \%$ & $0.01 \%$ & $0.03 \%$ \\
spike+shape & $89.93 \%$ & $8.17 \%$ & $1.65 \%$ & $0.01 \%$ & $0.24 \%$ \\
\hline
\end{tabular}

shift $1=$ shifts in the wavelength range $300-325 \mathrm{~nm}$

shift $2=$ shifts in the wavelength range $325-400 \mathrm{~nm}$,

start irr=irradiance level at which the readings start to become significant (i.e., noise in the spectrum below $25 \%$ of the signal), spike+shape $=$ local deviation from the expected spectral structure

was shadowing by people in front of the instrument during a maintenance event.

\subsection{European UV database}

Jokioinen and Sodankylä spectral UV data are regularly submitted to the European Database of UV radiation (EUVDB) (http://uv.fmi.fi/uvdb/index.html). At the EUVDB all incoming spectra undergo an automatic quality flagging process by the SHICrivm package developed by the RIVM, Netherlands (Slaper et al., 1995) (http://www.rivm.nl/shicrivm) and the CheckUVSpec package by the NILU, Norway (http://zardoz. nilu.no/ olaeng/CheckUVSpec/CheckUVSpec.html). The SHICrivm tool assigns to each spectrum quantitative quality indicators for wavelength scale errors, spikes and shape problems, lowest wavelength with accurate measurement, and atmospheric transmission. The CheckUVSpec tool assigns spectra with an atmospheric signature flag which is related to the prevailing atmospheric conditions. It should be noted that while some of the quality flags, e.g. wavelength scale errors, can be determined with high accuracy, problems with irradiance scale errors can only be detected if the error is very large.

Table 3 shows the summary of selected EUVDB quality flags related to errors and problems that can be determined with accuracy. The majority of the flags for both instruments are in the GREEN category, with some YELLOW flags in the spike and shape category, which is to be expected, because changing cloudiness causes spectral shape distortions. At Sodankylä, for example, $98 \%$ of the spectra are flagged as green for wavelength shifts, $99 \%$ for start irradiance, i.e., instrument sensitivity, and $95 \%$ for spike detection and shape problems. For Jokioinen the values are $99 \%, 99 \%$ and $90 \%$, respectively. In general, the number of RED, GREY and BLACK flags is very small, and in this respect the data can be 
considered of high quality. Further details about flagging can be found here: http://uv.fmi.fi/uvdb/html/flag_information. html http://www.muk.uni-hannover.de/ $\sim$ seckmeyer/EDUCE

\section{Conclusions}

Since the early 90's, spectral UV radiation has been measured with the Brewer spectrophotometers \#037 and \#107 at two sites in Finland. From the very beginning, special attention has been paid to the quality of these measurements, and a comprehensive quality assurance scheme has been developed. A lot of work has also been done on the characterization of the instruments, which has resulted in better monitoring of the instrument stability and improved postcorrection methods. This paper presents the quality assurance work and data processing scheme for the FMI spectral UV measurements. A future objective is to make a quantitative uncertainty analysis of these measurements.

At FMI, much effort has been put into the quality assurance of the spectral UV measurements, starting from careful training of the operators. Standard operating procedures include a daily routine check of the operation of the instrument, as well as regular lamp measurements in order to monitor the stability of the instruments. Since the late 90's, both of FMI's measurement sites have had a well-equipped laboratory dark-room that enables absolute calibration in a temperature-controlled environment with a $1000 \mathrm{~W}$ lamp. The lamp measurements are carried out varying the lamp set. This allows the use of lamps with different burn histories and a better identification of the lamp drifts.

The lamp measurements have been used to determine the whole spectral responsivity time series of the spectral UV measurements starting from 1990 and 1995 for Sodankylä and Jokioinen, respectively. The construction of the spectral responsivity time series is based on the transfer of the HUT irradiance scale to the whole time period, including also the first measurement years when only $50 \mathrm{~W}$ lamp measurements were available. The procedure normalizes the lamp measurements, as well as the whole time series, to the reference temperature. This is essential, because otherwise the temperature-dependent outdoor lamp calibrations would cause a seasonal calibration error.

The most important laboratory characterizations of the Brewer instruments have been carried out, and the whole of the spectral UV time series have been corrected and reprocessed using the results. The temperature characterization showed a linear temperature dependence that can be accounted for in postprocessing. Using the angular response measurements and a radiative transfer model, a wavelengthdependent cosine correction factor can be determined for each spectrum. The spectral resolution of the instrument has also been characterized, as well as the entrance optics. The processing software also includes corrections for noise spikes, dark current, dead time and stray light. The pro- cessing scheme can be applied to other spectroradiometers as well, assuming that the required instrument characteristics are available.

Intercomparisons with other spectroradiometers have showed good agreement within the measurement uncertainties. The latest comparison with the portable reference spectroradiometer QASUME showed a mean difference of around $5 \%$ for both Brewers. About half of this difference can be explained by differences in the irradiance scale, and the rest falls well within the measurement uncertainties.

Reconstructed UV dose rate data can contribute to quality assurance. They can be used to identify suspicious measurements that require more careful manual quality checking. A future objective is to implement this tool as part of the automated quality assurance process, so that the whole time series could be re-checked, and new measurements could be checked online. Reconstruction methods can also be used to produce UV spectra, which have a further potential for quality checking.

The spectral UV data of both Brewers are submitted to the European UV database (EUVDB) and can be downloaded at http://uv.fmi.fi/uvdb/index.html. All spectral UV data undergo an automatic flagging procedure at the EUVDB, and the results for the Finnish Brewers indicate good wavelength accuracy, and that anomalies in the spectra are very rare. It should be noted that the quality flagging does not give precise information about the accurary of the absolute calibration of the measurements.

Spectral UV data contain a lot of information about the atmosphere. Traditionally they have been used for monitoring of the ozone layer, but they also contain information on aerosols, trace gases, surface albedo, and clouds. Combined with other measurements and models, the long-term time series of spectral UV data can be used for versatile study of the changing climate.

Acknowledgements. The Academy of Finland has given financial support for this work through the FARPOCC project. We are grateful to the operators of the sounding stations at Sodankylä and Jokioinen for daily maintenance and for performing the lamp calibrations of the Brewer spectrometers. We thank the Nordic Ozone Group for organizing UV comparison campaigns. Harry Slaper (RIVM) is acknowledged for processing the data from the NOGIC-2000 intercomparison campaign, using the SHICrivm QA/QC software package (www.rivm.nl/shicrivm) and ancillary software for the determination of reference spectra from the campaign data. The QASUME spectroradiometer is made available by the Joint Research Centre of the European Commission in Ispra under cooperation agreement 2004-SOCP-22187. G. Hülsen acknowledges support from the Swiss European Cooperation in the field of Scientific and Technical Research (COST) office, SBF No.C05.0068.

Edited by: M. Blumthaler 


\section{References}

Aaltonen, V., Lihavainen, H., Kerminen, V.-M., Ginzburg, M., Kulmala, M., and Viisanen, Y.: Three years of AOD measurements at three bipolar sites, in: NOSA 2006 Aerosol symposium, combined with the X Finnish National Aerosol Symposium, FinnishCzech Aerosol Symposium, and BACCI workshop, Helsinki 8.10.11.2006, Report Series in Aerosol Science, 83, 17-20, 2006.

Arola, A., Kaurola, J., Koskinen, L., Tanskanen, A., Tikkanen, T., Taalas, P., Herman, J., Krotkov, N., and Fioletov, V.: A new approach to estimate the albedo for snow-covered surface in space-borne retrieval method, J. Geophys. Res., 108, 4531, doi:10.1029/2003JD003492, 2003a.

Arola, A., Lakkala, K., Bais, A., Kaurola, J., Meleti, C., and Taalas, P.: Factors affecting short- and long-term changes of spectral UV irradiance at two European stations, J. Geophys. Res., 108, 4549, doi:10.1029/2003JD003447, 2003b.

Arola, A., Lindfors, A., Natunen, A., and Lehtinen, K.: A case study on biomass burning aerosols: effects on aerosol optical properties and surface radiation levels, Atmos. Chem. Phys., 7, 4257-4266, 2007, http://www.atmos-chem-phys.net/7/4257/2007/.

Bais, A., Zerefos, C., and McElroy, C.: Solar UVB measurements with the double- and single-monochromator Brewer Ozone Spectrophotometers, Geophys. Res. Lett., 23, 833-836, 1996.

Bais, A., Kazadzis, S., Balis, D., Zerefos, C., and Blumthaler, M.: Correcting global solar ultraviolet spectra recorded by a Brewer spectroradiometer for its angular response error, Appl. Optics, 37, 6339-6344, 1998.

Bais, A., Gardiner, B., Slaper, H., Slaper, H., Blumthaler, M., Bernhard, G., McKenzie, R., Webb, A. R., Seckmeyer, G., Kjeldstad, B., Koskela, T., Kirsch, P. J., Gröbner, J., Kerr, J. B., Kazadzis, S., Leszczynski, K., Wardle, D., Brogniez, C., Josefsson, W., Gillotay, D., Reinen, H., Weihs, P., Svenœ, T., Eriksen, P., Kuik, F., and Redondas, A.: The SUSPEN intercomparison of ultraviolet spectroradiometers, J. Geophys. Res., 106, 12 509-12 525, 2001.

Bais, A., Blumthaler, M., Gröbner, J., Seckmeyer, G., Webb, A. R., Görts, P., Koskela, T., Rembges, D., Kazadzis, S., Schreder, J., Cotton, P., Kelly, P., Kouremeti, N., Rikkonen, K., Studemund, H., Tax, R., and Wuttke, S.: Quality assurance of spectral ultraviolet measurements in Europe through the development of a transportable unit (QASUME), in: Ultraviolet Ground- and Space-Based Measurements, Models, and Effects II, edited by: Gao, W., Herman, J. R., Shi, G., Shibasoki, K., and Slusser, J. R., SPIE 4896, 232-238, 2003.

Bais, A., Kazadzis, S., Garane, K., Kouremeti, N., Gröbner, J., Blumthaler, M., Seckmeyer, G., Webb, A., Koskela, T., Görts, P., and Schreder, J.: Portable device for characterizing the angular response of UV spectroradiometers, Appl. Optics, 44, 71367143, 2005.

Bernhard, G. and Seckmeyer, G.: Uncertainty of measurements of spectral solar UV irradiance, J. Geophys. Res., 104, 14321$14345,1999$.

Bernhard, G., Booth, C. R., and Ehramjian, J. C.: Version 2 data of the National Science Foundation Ultraviolet Radiation Monitoring Network: South Pole, J. Geophys. Res., 109, doi: 10.1029/2004JD005584, 2004.

Bernhard, G., Booth, C. R., and Ehramjian, J. C.: Real-time ultraviolet and column ozone from multichannel ultraviolet radiometers deployed in the National Science Foundations ultraviolet monitoring network, Opt. Eng., 44, 2005.

Blumthaler, M.: Quality assurance and quality control methodologies used within the Austrian UV monitoring network, Radiation Protection Dosimetry, 111, 359-362, doi:10.1093/rpd/nch054, 2004.

Booth, C., Lucas, T., and Morrow, J.: High resolution UV spectral irradiance monitoring program in polar regions: Five years (and growing) of data available to polar research in ozone- and ultraviolet -related studies, Antarct. J. U. S., pp. 338-341, 1992.

Booth, C., Bernhard, G., Ehramjian, J., Quang, V., and Lynch, S.: NSF Polar Programs UV Spectroradiometer Network 1999-2000 Operations Report, Tech. rep., Biospherical Instruments Inc., San Diego, 219 pp., 2001.

Cappellani, F. and Kochler, C.: Temperature effects correction in a Brewer MKIV spectrophotometer for solar UV measurements, J. Geophys. Res., 105, 4829-4831, 1999.

De Backer, H., Köpke, P., Bais, A., De Cabo, X., Frej, T., Gillotay, D., Haite, C., Heikkilä, A., Kazantzidis, A., Koskela, T., Kyrö, E., Lapeta, B.and Lorente, J., Masson, K., Mayer, B., Plets, H., Redondas, A., Renaud, A., Schauberger, G., Schmalwieser, A., and Vaniceck, K.: Comparison of measured and modelled UV indices for the assessment of health risks., Meteorol. Appl. 8, 267-277, 2001.

Feister, U., Grewe, R., and Gericke, K.: A method for correction of cosine errors in measurements of spectral UV irradiance, Solar Energy, 60, 313-332, 1997.

Garane, K., Bais, A., Kazadzis, S., Kazantzidis, A., and Meleti, C.: monitoring of UV spectral irradiance at Thessaloniki (19902005): data re-evaluation and quality control, Ann. Geophys., 24, 3215-3228, 2006, http://www.ann-geophys.net/24/3215/2006/.

Gardiner, B. G. and Kirsch, P. J.: Intercomparison of ultraviolet spectroradiometers, Ispra, 24-25 May 1995, in: Advances in Solar Ultraviolet Spectroradiometry, Air Pollut. Res. Rep. 63, edited by: Webb, A. R., 67-151, Eur. Commun., Luxembourg, 1997.

Glandorf, M., Arola, A., Bais, A., and Seckmeyer, G.: Possibilities to detect trends in spectral UV irradiance, Theoretical and Applied Climatology, 81, 33-44, doi:10.1007/s00704-004-0109-9, 2005.

Gröbner, J. and Sperfeld, P.: Direct traceability of the portable QASUME irradiance standard of the PTB, Meteorologia, 42, 134139, 2005.

Gröbner, J., Rembges, D., Bais, A. F., Blumthaler, M., Cabot, T., Josefsson, W., Koskela, T., Thorseth, T. M., Webb, A. R., and Wester, U.: Quality Assurance of Reference Standards From Nine European Solar-Ultraviolet Monitoring Laboratories, Appl. Optics, 41, 4278-4282, 2002.

Gröbner, J., J., S., Kazadzis, S., Bais, A. F., Blumthaler, M., Görts, P., Tax, R., Koskela, T., Seckmeyer, G., Webb, A. R., and Rembges, D.: Traveling reference spectroradiometer for routine quality assurance of spectral solar ultraviolet irradiance measurements, Appl. Optics, 44, 5321-5331, 2005.

Huttunen, S., Taipale, T., Lappalainen, N. M., Kubin, E., Lakkala, K., and Kaurola, J.: Environmental specimen bank samples of Pleurozium schreberi and Hylocomium splendens as indicators of the radiation environment at the surface, Environ. Pollut., 133, 315-326, 2005.

Josefsson, W.: UV radiation 1983-2003 measured at Norrköping, 
Sweden, Theor. Appl. Climatol., 83, 59-76, doi:10.1007/ s00704-005-0160-1, 2006.

Kazantzidis, A., Bais, A. F., Gröbner, J., Herman, J. R., Kazadzis, S., Krotkov, N., Kyrö, E., den Outer, P. N., Garane, K., Görts, P., Lakkala, K., Meleti, C., Slaper, H., Tax, R. B., Turunen, T., and Zerefos, C. S.: Comparison of satellite-derived UV irradiances with ground-based measurements at four European stations, J. Geophys. Res., 111, doi:10.1029/2005JD006672, 2006.

Kjeldstad, B., Johnsen, B., and Koskela, T.: The Nordic Intercomparison of Ultraviolet and Total Ozone Instruments at Izaña, October 1996. Final Report., 36, Meteorologisia julkaisuja, Ilmatieteen laitos, Helsinki, 1997.

Koskela, T.: The Nordic Intercomparison of ultraviolet and total ozone instruments at Izaña from 24 October to 5 November 1993. Final report, 27, Meteorologisia julkaisuja, Ilmatieteen laitos, Helsinki, 1994.

Koskela, T.: On the stability of an irradiance calibration lamp, in: Extended Abstracts of the 2nd Workshop at PTB, Braunschweig 9-11 November 1998, the Thematic Network on UV Measurements, UVNEWS, Issue 2, ISSN 1456-2537, 30-31, http://metrology.hut.fi/uvnet/source/UVNEWS2.htm, 1999.

Kübarsepp, T., Kärhä, P., Manoocheri, F., Nevas, S., Ylianttila, L., and Ikonen, E.: Spectral irradiance measurements of tungsten lamps with filter radiometers in the spectral range $290 \mathrm{~nm}$ to 900 nm, Meteorologia, 37, 305-312, 2000.

Kyrö, E.: Spectral Lamp and HeCd-Laser Measurements, in: The Nordic Intercomparison of Ultraviolet and Total Ozone Instruments at Izaña, October 1996. Final report., edited by: Kjeldstad, B., Johnsen, B., and Koskela, T., 36, Meteorologisia julkaisuja, 79-88, Ilmatieteen laitos, helsinki, 1997.

Kyrö, E., Taalas, P., Jörgensen, T., Knudsen, B., Stordal, F., Braahten, G., Dahlback, A., Neuber, R.and Krüger, B., Dorokhov, V., Yushkov, V., Rudakov, V., and Torres, A.: Analysis of the ozone soundings made during the first quarter of 1989 in the Arctic, J. Geophys. Res., 8083-8091, 1992.

Lakkala, K., Kyrö, E., and Turunen, T.: Spectral UV Measurements at Sodankylä during 1990-2001, J. Geophys. Res., 108, doi:10. 1029/2002JD003300, 2003.

Lakkala, K., Redondas, A., Meinander, O., Torres, C., Koskela, T., Cuevas, E., Taalas, P., Dahlback, A., Deferrari, G., Edvardsen, K., and Ochoa, H.: Quality assurance of the solar UV network in the Antarctic, J. Geophys. Res., 110, doi:10.1029/ 2004JD005584, 2005.

Landelius, T. and Josefsson, W.: Methods for cosine correction of broadband UV data and their effect on the relation between UV irradiance and cloudiness, J. Geophys. Res., 105, 4795-4802, 2000.

Lindfors, A., Kaurola, J., Arola, A., Koskela, T., Lakkala, K., Josefsson, W., Olseth, J. A., and Johnsen, B.: A method for reconstruction of past UV radiation based on radiative transfer modeling: applied to four stations in northern Europe, J. Geophys. Res., 112, doi:10.1029/2007JD008454, 2007.

Lindfors, A. V., Arola, A., Kaurola, J., Taalas, P., and Svenøe, T.: Long-term erythemal UV doses at Sodankylä estimated using total ozone, sunshine duration, and snow depth, J. Geophys. Res., 108, doi:10.1029/2002JD003325, 2003.

Mayer, B. and Kylling, A.: Technical note: the libRadtran software package for radiative transfer calculations-Description and examples of use, Atmos. Chem. Phys., 5, 1855-1877, 2005, http://www.atmos-chem-phys.net/5/1855/2005/.

Meinander, O., Josefsson, W., Kaurola, J., Koskela, T., and Lakkala, K.: Spike detection and correction in Brewer spectroradiometer UV spectra, Opt. Eng., 42, 1812-1819, 2003.

Meinander, O., Kazadzis, S., Blumthaler, M., Ylianttila, L., Johnsen, B., Lakkala, K., Koskela, T., and Josefsson, W.: Diurnal discrepancies in spectral solar UV radiation measurements, Appl. Optics, 45, 5346-5357, 2006.

Seckmeyer, G. and Bernhard, G.: Cosine Error Correction of spectral UV-irradiances, Atmospheric Radiation, 2049, 140/SPIE, 1993.

Seckmeyer, G., Bais, A., Bernhard, G., Blumthaler, M., Booth, C., Disterhoft, P., Eriksen, P., McKenzie, R., Miyauchi, M., and Roy, C.: Instruments to Measure Solar Ultraviolet Radiation, Part 1: Spectral instruments, Tech. Rep. 125, WMO TD 1066, 2002.

Slaper, H. and Koskela, T.: Methodology of intercomparing spectral sky measurements, in: The Nordic Intercomparison of Ultraviolet and Total Ozone Instruments at Izaña, October 1996. Final Report., edited by: Kjeldstad, B., Johnsen, B., and Koskela, T., 36, Meteorologisia julkaisuja, 89-108, Ilmatieteen laitos, Helsinki, 1997.

Slaper, H., Reinen, H. A. J. M., Blumthaler, M., Huber, M., and Kuik, F.: Comparing ground-level spectrally resolved solar UV measurements using various instruments: A technique resolving effects of wavelength shift and slit width, Geophys. Res. Lett., 22, 2721-2724, 1995.

Tanskanen, A., Lindfors, A., Määttä, A., Krotkov, N., Herman, J., Kaurola, J., Koskela, T., Lakkala, K., Fioletov, V., Bernhard, G., McKenzie, R., Kondo, Y., O’Neill, M., Slaper, H., den Outer, P., Bais, A. F., and Tamminen, J.: Validation of daily erythemal doses from Ozone Monitoring Instrument with ground-based UV measurement data, J. Geophys. Res., 112, doi: 10.1029/2007JD008830, 2007.

Thorseth, T., Kjeldstad, B., Johnsen, B., Blumenthaler, M., Lakkala, K., and Slaper, H.: Results from the Nordic Intercomparison of ultraviolet spectroradiometers in Sweden 2000, in: Geophysical Research Abstracts. Abstracts of the Contributions of the 27th General Assembly of the European Geophysical Society, Nice, France, 21-26 April 2002., 4, 2002.

Von der Gathen, P., Rex, M., Harris, N. R. P., Lucic, D., Knudsen, B. M., Braathen, G. O., de Backer, H., Fabian, R., Fast, H., Gil, M., Kyrö, E., Mikkelsen, I. S., Rummukainen, M., Staehelin, J., and Varotsos, C.: Observational evidence for chemical ozone depletion over the Arctic in winter 1991-92, Nature, 375, 131134, 1995.

Weatherhead, E., Theisen, D., Stevermer, A., Enagonio, J., Rabinovitch, B., Disterhoft, P., Lantz, K., Meltzer, R., Sabburg, J.and DeLuisi, J., Rives, J., and Shreffler, J.: Temperature dependence of the Brewer ultraviolet data, J. Geophys. Res., 106, 34 121-34 129, 2001.

Webb, A., Gardiner, B., Martin, T., Leszcynski, K., Metzdorf, J., and Mohnen, V.: Guidelines for Site Quality Control of UV Monitoring, Tech. Rep. 126, World Meteorological Organization, Global Atmosphere Watch, 1998.

Webb, A., Gardiner, B., Leszczynski, K., Mohnen, V., Johnston, P., Harrison, N., and Bigelow, D.: Quality Assurance in Monitoring Solar Ultraviolet Radiation: the State of the Art, Tech. Rep. 146, World Meteorological Organization, Global Atmosphere Watch, 2003. 
Wehrli, C.: Calibrations of Filter Radiometers for Determination of Atmospheric Optical Depth, Meteorologia, 37, 419-422, 2000.

WMO: Scientific Assessment of Stratospheric ozone: 1989. Report No. 20 in 2 volumes, World Meteorological Organization, Geneva, 1990.
Ylianttila, L. and Schreder, J.: Temperature effects of PTFE diffusers, Optical Materials, 27, 1811-1814, doi:10.1016/j.optmat. 2004.11.008, 2005.

Young, A., Björn, L., Moan, J., and Nultsch, W.: Environmental UV Photobiology, Plenum Press, New York, 1993. 